\title{
Characterization of a Bifacial Photovoltaic Panel Integrated with External Diffuse and Semimirror Type Reflectors
}

\author{
P. Ooshaksaraei, ${ }^{1,2}$ K. Sopian, ${ }^{1}$ R. Zulkifli, ${ }^{2}$ M. A. Alghoul, ${ }^{1}$ and Saleem H. Zaidi ${ }^{1}$ \\ ${ }^{1}$ Solar Energy Research Institute, Universiti Kebangsaan Malaysia (UKM), 43600 Bangi, Selangor, Malaysia \\ ${ }^{2}$ Department of Mechanical \& Materials Engineering, Faculty of Engineering \& Built Environment, \\ Universiti Kebangsaan Malaysia (UKM), 43600 Bangi, Selangor, Malaysia \\ Correspondence should be addressed to P. Ooshaksaraei; poorya@eng.ukm.my
}

Received 25 September 2012; Revised 18 April 2013; Accepted 4 May 2013

Academic Editor: Peter Rupnowski

Copyright (C) 2013 P. Ooshaksaraei et al. This is an open access article distributed under the Creative Commons Attribution License, which permits unrestricted use, distribution, and reproduction in any medium, provided the original work is properly cited.

\begin{abstract}
Silicon wafer accounts for almost one-half the cost of a photovoltaic (PV) panel. A bifacial silicon solar cell is attractive due to its potential of enhancing power generation from the same silicon wafer in comparison with a conventional monofacial solar cell. The bifacial PV cell is able to capture solar radiation by back surface. This ability requires a suitable reflector appropriately oriented and separated from the cell's rear surface. In order to optimize the bifacial solar cell performance with respect to an external back surface reflector, diffuse and semimirror reflectors were investigated at various angles and separations from the back surface. A simple bifacial solar panel, consisting of four $5^{\prime \prime} \times 5^{\prime \prime}$ monocrystalline Si solar cells, was designed and built. Reflection from the rear surface was provided by an extended semimirror and a white-painted diffuse reflector. Maximum power generation was observed at $30^{\circ}$ with respect to ground for the semimirror reflector and $10^{\circ}$ for diffuse reflector at an optimized reflector-panel separation of $115 \mathrm{~mm}$. Output power enhancement of $20 \%$ and $15 \%$ from semimirror and diffuse reflectors, respectively, were observed. This loss from diffuse reflector is attributed to scattering of light beyond the rear surface capture cross-section of the bifacial solar panel.
\end{abstract}

\section{Introduction}

Figure 1 schematically draws conventional monofacial and bifacial silicon solar cell cross-sectional configurations [1]. In monofacial solar cells, the front surface is transparent with glass lamination, and the back surface is opaque (Figure 1(a)). Front surface of the solar cell absorbs the sunlight and converts it into electricity with a metallic grid pattern on the front surface and a blanket metal film on the rear surface. In some field applications, PV panels are installed in such a way that rear surface is able to capture diffuse reflected light from ground and other reflective surfaces surrounding the panel. In order to capture this diffuse radiation, researches in 80 s led to development of a new generation of solar cells able to absorb solar radiation from rear surface [2]. This type of solar cell is referred to as a bifacial solar cell. A bifacial solar cell, in contrast with a monofacial solar cell, has identical metallic grids on both front and back surfaces (Figure 1(b)). Some modifications to conventional monofacial PV panel design are required in order to effectively utilize the bifacial
PV panel. This research is aimed at evaluating the bifacial PV panel output variation with single semimirror and diffuse reflectors.

1.1. Bifacial Solar Cell. Bifacial solar cell has the potential to absorb additional sunlight by rear surface, which is a significant advantage in contrast with the monofacial solar cell. Additional solar radiation absorption through the bifacial solar cell's rear surface leads to enhanced electrical power generation [3].

A key challenge in effective utilization of bifacial solar cells is in the design of appropriate rear surface reflector. The effect of external rear surface reflector for bifacial solar cells has been investigated for residential applications [4] including reflection from wall, capture of radiation reflected back by window, and terrestrial reflection in parking lot. In such applications, existence of an appropriate reflector is a critical element in order to substantially increase solar radiation incident on rear surface. However, there are many 


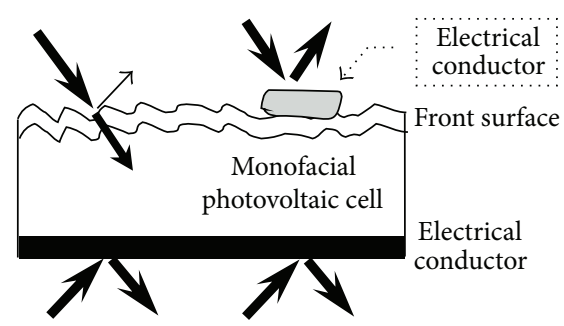

(a)

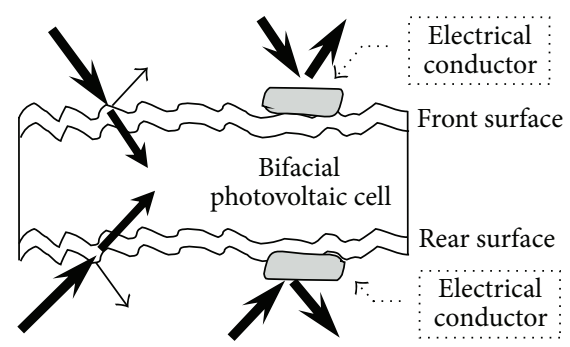

(b)

Figure 1: Cross-section configurations of monofacial (a) and bifacial solar cells (b).

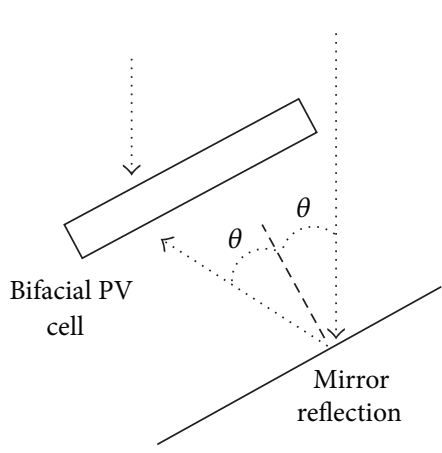

(a)

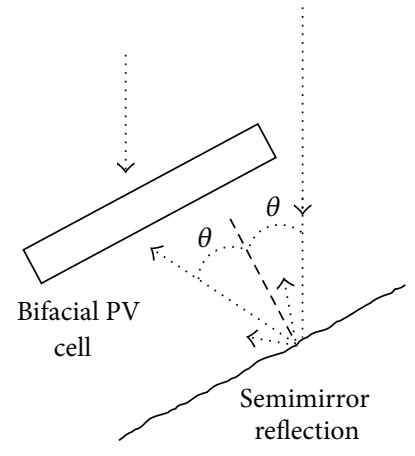

(b)

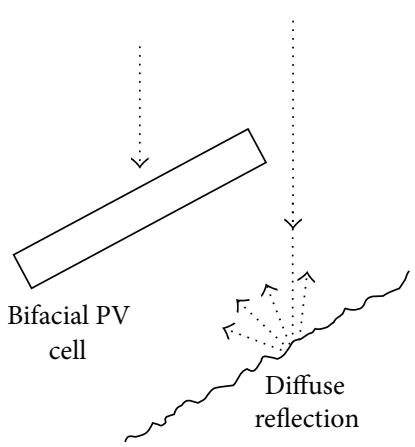

(c)

FIGURE 2: Bifacial PV panel integrated with mirror type reflector (a); semimirror type reflector (b); and diffuse type reflector (c).

cases in which bifacial solar panels are effective without the reflector $[5,6]$. The slope and direction of bifacial solar panel play a significant role in maximizing the solar radiation absorption and have been investigated for bare bifacial solar panels, that is, without external reflectors, by Joge et al. [7]. Installation attitude of bare bifacial panels has been studied by Joge et al. [7], where little dependence between orientation and annual power generation was observed. This research has been followed by Uematsu et al. and proved bare bifacial panels as an orientation-free device [6].

Their work defined the bifaciality parameter as the ratio of rear surface efficiency over front surface efficiency:

$$
\text { bifaciality }=\frac{\text { rear surface efficiency }}{\text { front surface efficiency }} \text {. }
$$

This definition is based on the assumption that the same intensity of solar radiation is incident on both rear and front surfaces.

1.2. Reflector. In bare bifacial panel applications such as fence integration, front surface usually faces the sun, while the rear surface captures diffuse sky radiation and/or ground reflection based on panel orientation and time of the day. With two absorption surfaces, bifacial solar panels produce more electrical energy than monofacial panels especially in cloudy climates [7]. Bifacial solar panels equipped with external reflectors are expected to generate additional electrical energy depending on the materials properties of the reflector and its location. Some of the key parameters for the reflector include its slope with respect to the panel plane, distance from the panel, and reflection efficiency.

In general, solar panels are classified either as one-sun (1X) panel or concentrator panel (multi X). For the case of bifacial panels the definition of flat panel and concentrator panel may overlap in case where the front surface receives $1 \mathrm{X}$ solar radiation, while the rear surface may receive additional $1 \mathrm{X}$ beam radiation [8]. Mirror type, diffuse type, and semitransparent reflection have been investigated for various bifacial PV panel applications [9-13]. Uematsu et al. [14] developed a flat plate bifacial panel by static V-groove concentrator to provide $1 \mathrm{X}$ solar radiation on rear surface of bifacial cell, which resulted in $85.6 \%$ enhancement in power.

A wide range of reflectors including diffuse, mirror, and semitransparent has been studied in the literature $[4,9$, 10, 14]. Figure 2 represents a simple schematic of bifacial PV panel integrated with an external reflector. Figure 2(a) represents a mirror type reflection where only one beam of light is directed to the rear surface of the panel, while diffuse reflector scatters the reflected radiation over the rear surface of the bifacial panel/cell (Figure 2(c)).

The semimirror reflector shown in Figure 2(b) reflects back a portion of solar radiation on rear surface, like a mirror type reflector, while a portion of solar radiation is scattered.

Reflection is a function of surface roughness as well as its color [15]. Duran et al., demonstrated that variation in solar radiation intensity on rear surface leads to a corresponding variation in electricity generation [16]. Moehlecke et al., [15] studied the reflection performance of painted diffuse 


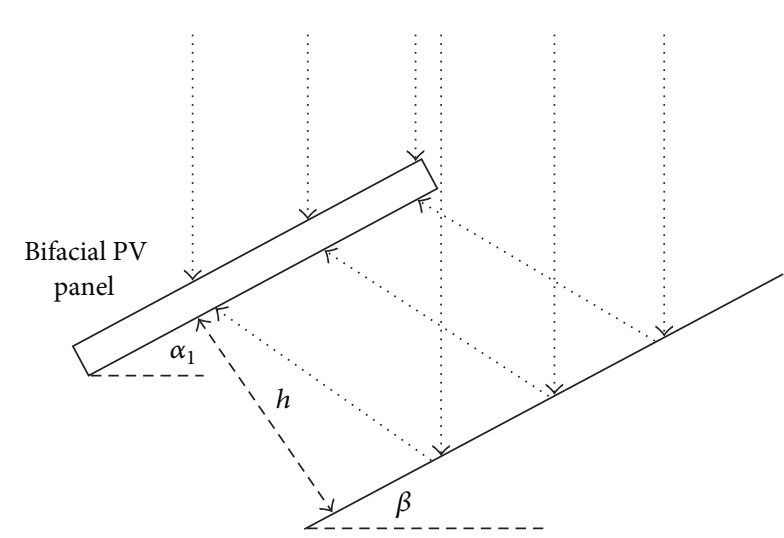

(a)

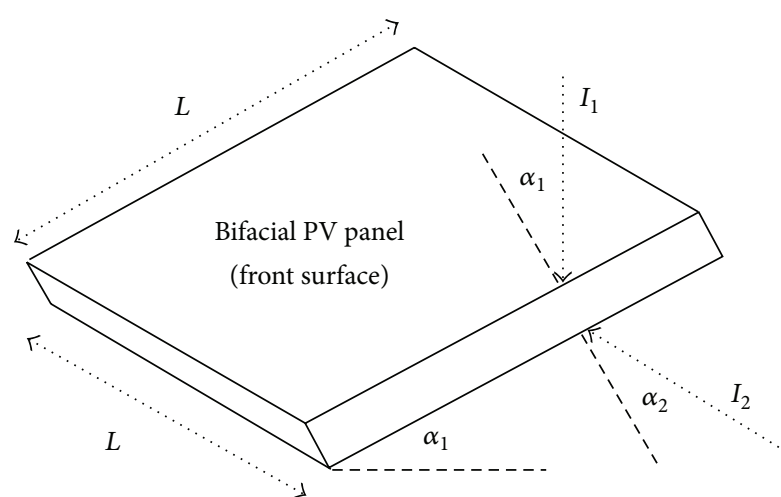

(b)

FIGURE 3: Bifacial panel integrated with an external mirror reflector (a) and schematic diagram of the incident solar radiation on front and back surfaces of bifacial solar panel of area $L^{2}(\mathrm{~b})$.

reflectors placed under bifacial solar panels. Enhancement up to $25 \%$ in solar absorption in comparison with conventional monofacial PV panel was demonstrated. Their work indicated that white color was an optimum diffuse painted reflector with approximately $75 \%$ average reflectance. Yellow color has the second best reflection performance followed by orange, red, green, blue, brown, purple, grey, dark blue, and dark green with $61 \%-32 \%$ reflection variation [15]. Reflection performance of a reflector is not only a function of its color but also the direction of the incident beam as well as the microstructure of the reflector.

\section{Mathematical Formalism}

Work reported in the literature suggests that a variety of reflectors can be applied to a bifacial panel. A white surface as an optimum color painted reflector and an aluminum plate as a semimirror type reflector were chosen for the work reported here. Aluminum plate was selected due to its affordability, durability, and higher reflectance.

Figure 3(a) is a graphical representation of bifacial panel integrated with an external reflector being modeled here.

The panel-reflector separation facilitates the reflection of solar radiation on rear surface of the panel. In Figure 3(b), the front surface of the panel receives the direct solar radiation $I_{1}$, while the rear surface receives the radiation reflected back from reflector $I_{2}$. $L$ denotes the dimension of the panel.

There are three key parameters in a bifacial panel equipped with an external reflector under the panel, namely, slope of the reflector $(\beta)$, slope of the PV panel $\left(\alpha_{1}\right)$, and average distance between the PV panel and the reflector $(h)$, to be referred to as separation (Figure $3(\mathrm{a})$ ); $\alpha_{1}$ and $\beta$ denote the slope of bifacial panel and the slope of the reflector plate, respectively; $I_{1}$ and $I_{2}$ denote radiation incident on PV panel at angles $\alpha_{1}$ and $\alpha_{2}$ from normal to the surface (Figure 3(b)).

2.1. Bifaciality of the Solar Panel. Bifaciality of a bifacial solar cell only depends on the efficiency of the front and rear surfaces and has been defined in (1), while the bifaciality of a PV panel has been defined as

$$
\begin{aligned}
\text { panel bifaciality } & =\frac{\text { rear surface electrical output }}{\text { front surface electrical output }} \\
& =\frac{E_{\text {rear }}}{E_{\text {front }}}
\end{aligned}
$$

where $E_{\text {rear }}$ and $E_{\text {front }}$ are related to rear and front surface efficiencies as follows:

$$
\begin{aligned}
& \eta_{\mathrm{PV}_{\text {front }}}=\frac{E_{\text {front }}}{I_{1} \cos \left(\alpha_{1}\right)}, \\
& \eta_{\mathrm{PV}_{\text {rear }}}=\frac{E_{\text {rear }}}{I_{2} \cos \left(\alpha_{2}\right)} .
\end{aligned}
$$

From (1), the bifaciality factor of a bifacial cell has been defined as [7]

$$
K_{\text {bif }}=\frac{\eta_{\mathrm{PV}_{\text {rear }}}}{\eta_{\mathrm{PV}_{\text {front }}}} .
$$

Reflection performance of the reflector is a nondimensional parameter and is the ratio of intensity of reflected radiation over the intensity of radiation reaching the reflector surface:

$$
\eta_{\text {reflector }}=\frac{I_{2}}{I_{1}} .
$$

Substituting (3), (4), (5), in (2), the panel bifaciality may be redefined as

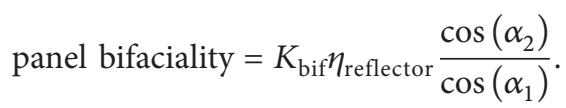

Since the rear and front surfaces represent the opposite surfaces of the same bifacial cell, $\eta_{\mathrm{PV} \text { front }}$ and $\eta_{\mathrm{PV} \text { rear }}$ can be measured by exposing front aperture and rear surfaces 
alternatively during panel output power measurements. Both rear and front apertures must receive the same intensity of solar radiation during the measurement in order to calculate (4). Since both the rear and front surfaces have the same absorber area, (4) can be rewritten as

$$
K_{\text {bif }}=\frac{\eta_{\mathrm{PV}_{\text {rear }}}}{\eta_{\mathrm{PV}_{\text {front }}}}=\frac{E_{\mathrm{PV}_{\text {rear }}}}{E_{\mathrm{PV}_{\text {front }}}},
$$

where $E_{\mathrm{PVfront}}$ and $E_{\mathrm{PV} \text { rear }}$ denote the electrical energy production by rear and front surfaces, respectively. Please note that part of incident beam radiation penetrates $P V$ cell, during $E_{\mathrm{PVfront}}$ measurement, and reaches rear surfaces, which leads to additional power generation based on transmittance/absorption characteristics of front and rear surfaces of the bifacial PV cell. There is similar bias error in $E_{\mathrm{PV} \text { rear }}$ measurement as well. Since the cell structure is symmetric, this contribution can be ignored as it cancels out.

2.2. Total Panel Efficiency. The electrical energy generated by the rear surface of the bifacial solar panel strongly depends on the efficiency of the reflector placed under the cell. The total efficiency of bifacial panel is defined as

$$
\eta_{\text {panel }}=\eta_{\mathrm{PV}_{\text {front }}} \tau_{\mathrm{Glass}} P+\eta_{\mathrm{PV}_{\text {rear }}} \tau_{\mathrm{Glass}} \eta_{\text {Reflector }} P,
$$

where $\eta_{\text {PVfront }}$ and $\eta_{\text {PVrear }}$ denote the efficiency of the front and rear surfaces of the bifacial panel, respectively. $\tau_{\text {Glass}}$, $\eta_{\text {Reflector}}$, and " $P$ " denote the transmittance of the panel glazing, reflection performance of the reflector, and the packing factor of the panel, respectively.

The packing factor of a PV panel is a nondimensional factor defined as the ratio of effective absorber area of solar cells over the total panel area of the panel facing solar radiation. That is, in case of a four-cell panel, the packing factor is defined as the total area of the four cells $(4 \times a \times b)$ divided by the total area of the panel $(L \times L)$; please refer to Figure 4.

Equation (8) applies to a bifacial panel where the solar radiation is reflected back by an external reflector. In a bifacial panel with an external reflector, the dimensions of reflector are generally larger than that of the panel. A plot of (8) as a function packing factors is drawn in Figure 5.

The transparent vacant spaces between the solar cells impact the total efficiency of the panel. These transparent spaces provide open regions through which the solar radiation can pass through and reflect back to the rear surface of the panel. Therefore, the electrical energy generated by the rear surface strongly depends on the panel packing factor. The lower packing factor leads to higher solar radiation on rear aperture. Therefore, there is a tradeoff between total energy generated and the optimum packing factor, that is, a function of several factors including cost effectiveness.

Neglecting the mirror extension from panel length and considering a reflector at same size of the panel, all solar radiation captured by the rear surface originates from vacant space between cells. Therefore, total efficiency of such panel is defined as

$$
\eta_{\text {panel }}=\eta_{\mathrm{PV}_{\text {front }}} P+\eta_{\mathrm{PV}_{\text {rear }}}(1-P) \tau_{\mathrm{Glass}} \eta_{\text {Rear }} P,
$$

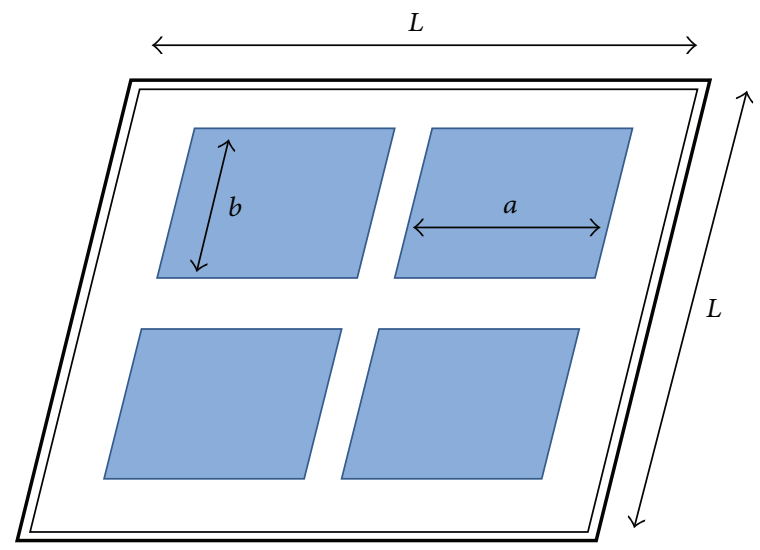

FIGURE 4: A four-cell PV panel with total absorber area of $4 a b$ and the laminated panel area of $L^{2}$.

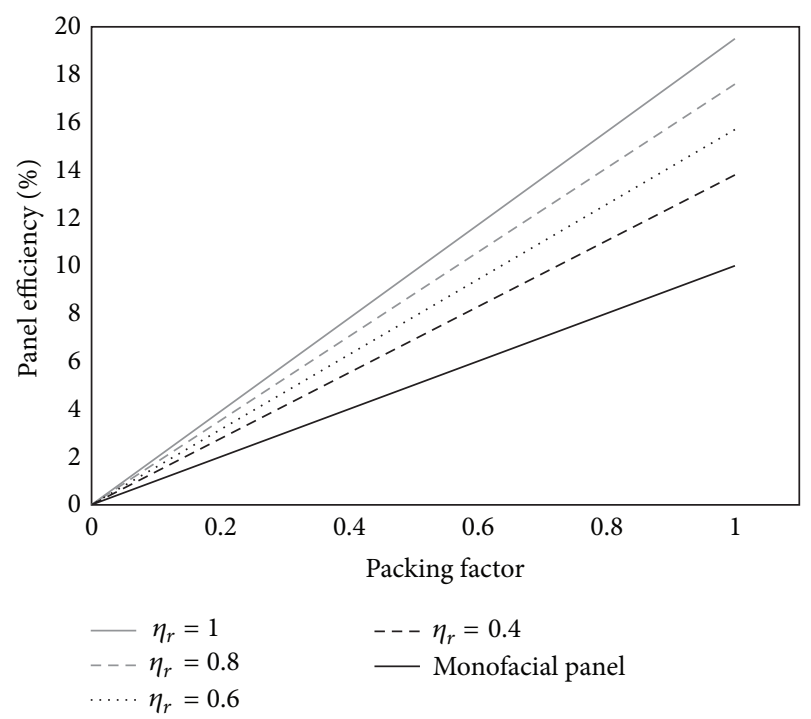

FIGURE 5: Variation of total efficiency of a bifacial panel as a function of packing factor.

where $\eta_{\text {PVfront }}$ and $\eta_{\text {PVrear }}$ denote the efficiency of the front and rear surfaces of the bifacial panel, respectively. $\tau_{\text {Glass }}$, $\eta_{\text {Reflector}}$, and " $P$ " denote the transmittance of the panel glazing, reflection performance of the reflector, and the packing factor of the panel respectively.

A plot of the panel total efficiency (9) as a function of the packing factor in Figure 6 reveals nonlinear response. The panel efficiency represented in Figure 6 is a function of reflector efficiency and packing factor in accordance with (9).

Comparing simulations in Figures 5 and 6, benefits of external reflector are clarified in terms of enhanced power output.

\section{Results and Discussion}

Four $5^{\prime \prime} \times 5^{\prime \prime}$ monocrystalline bifacial cells were used to fabricate a glass to transparent Tedlar for indoor characterization. 


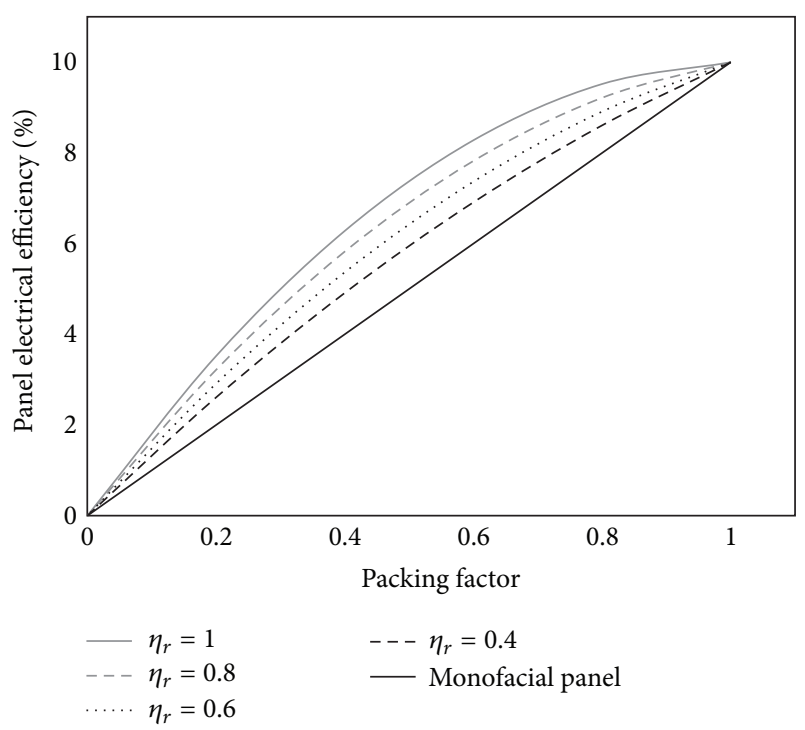

FIGURE 6: Variation of the total panel efficiency of equally sized panel and reflectors as a function packing factor.

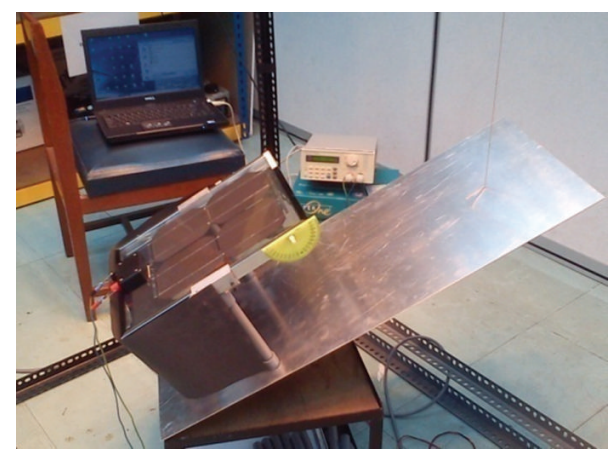

FIGURE 7: Experimental configuration for indoor bifacial solar panel integrated with an external reflector.

The cells were manufactured by Hitachi Company with technical details as follows:

(i) wafer thickness: 200 micrometer,

(ii) wafer type: $\mathrm{p}$ type (boron doped),

(iii) texture: inverted pyramids,

(iv) front surface: AR film, $\mathrm{SiN}$,

(v) back surface: AR film, $\mathrm{SiO}_{2}$,

(vi) front surface: phosphorous doped,

(vii) back surface: boron doped.

The bifacial PV panel has packing factor of 0.69 and was integrated with a single external reflector located under the panel as shown in Figure 7. Two types of reflectors have been used for indoor characterization work: an aluminum reflector and white-painted aluminum reflector.

The efficiency of the front and rear surfaces has been measured separately. The bifaciality of the panel $\left(K_{\text {bif }}\right)$ has been measured under solar simulator (indoor test) as a function
TABLE 1: Bifacial factor measurements as a function of slope angle.

\begin{tabular}{lccccccc}
\hline Panel slope (degree) & 0 & 10 & 20 & 30 & 40 & 50 & Average \\
$K_{\text {bif }}$ & 1 & 1 & 0.98 & 0.96 & 0.94 & 0.92 & 0.97 \\
\hline
\end{tabular}

of the panel slope in zero-to-50-degree range. Measurement results have been summarized in Table 1 .

There was no reflector under the panel during $K_{\mathrm{bif}}$ measurements. The efficiency of the front surface was measured with it facing the lamps (solar simulator) while the rear surface was protected by a black cover. Likewise, the efficiency of the rear surface was measured with the rear surface facing the lamps and front surface protected by a black cover. The bifaciality factor is reduced as the panel tilt angle increases, which may be attributed to larger reflection losses from the rear surface. Assuming identical microstructures on front and rear surfaces of the solar cell, this loss may be due to different optical response of front and rear surfaces. In the bifacial solar cells reported here, the front surface antireflection film was silicon nitride, and the back surface antireflection film was silicon dioxide. It is well known that silicon nitride has higher index of refraction and performs better than silicon dioxide.

In order to calculate the total efficiency of the bifacial panel, a reflector was placed under the panel. The panel and the reflector were parallel during the tests $\left(\alpha_{1}=\beta\right)$, but the panel separation $(h)$ from the reflector was adjustable. The PV cell separation from reflector $(h)$ and the slope of panel $\left(\alpha_{1}\right)$ are the two key parameters. The electrical power output was measured as a function of panel slope angle in $0^{\circ}$ to $50^{\circ}$ range has been plotted in Figure 8; cell-reflector separation was varied from $75 \mathrm{~mm}$ to $215 \mathrm{~mm}$.

Both diffuse and semimirror reflectors exhibit similar contribution in electrical energy generation enhancement by the bifacial panel. A panel with packing factor of 0.69 has transparent spaces in between adjacent solar cells. At least, thirty-one $\%$ of incident solar radiation (31\%) passes through the gaps between the solar cells and is reflected back to the rear surface of the panel. At panel slope equal to zero, the gaps between the cells are the only source of radiation for rear surface. A panel with high packing factor strongly depends on extended reflector to achieve the optimum performance. Regardless of the panel separation, the optimum performance was observed at tilted panel (Figure 8).

The average output power of the panel tilted from zero to $50^{\circ}$ is shown in Figure 9. In Figure 9, the "front surface" denotes the output power measured while the rear aperture is blocked and vice versa.

The bifacial panel outfitted by a semimirror type reflector represents the maximum total efficiency at the panel at panel separation $115 \mathrm{~mm}$, while in case of the diffuse reflector, the maximum efficiency was observed at $75 \mathrm{~mm}$ and $115 \mathrm{~mm}$ (Figure 9). Effect of the bifacial PV panel separation from reflector on the average electrical power output of the panel is shown in Figure 9, where the output power of the front and the rear apertures is shown separately. The "semimirror" and "diffuse" denote the total electrical power generated by 


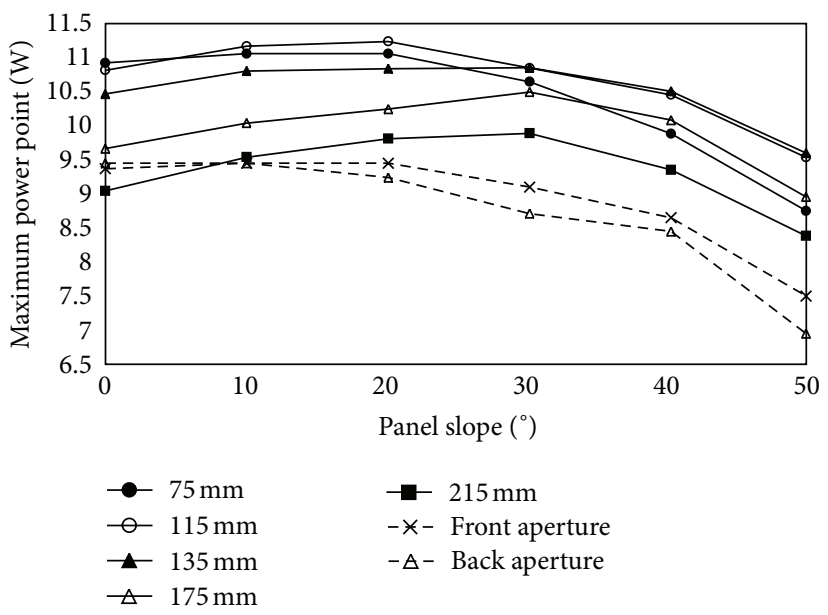

(a)

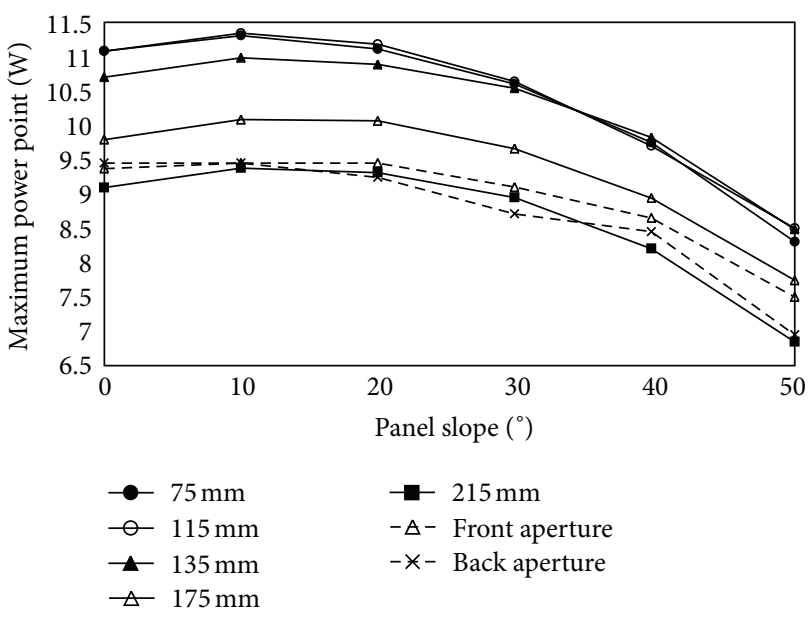

(b)

FIGURE 8: Plot of maximum power point for semimirror reflector (a) and diffuse reflector (b).

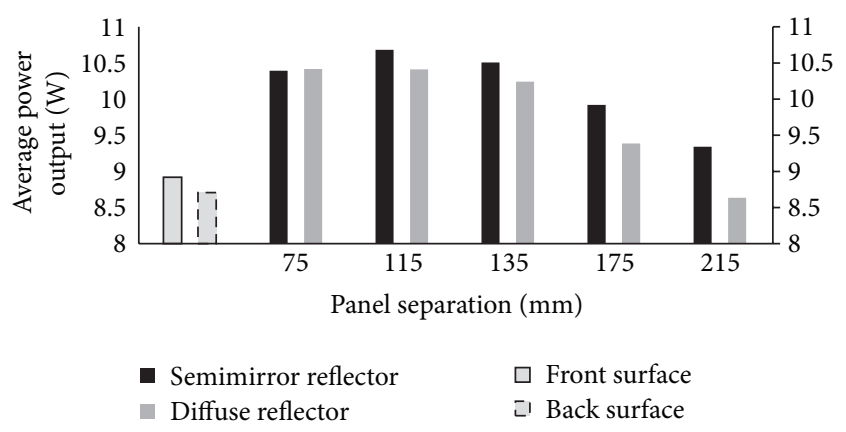

FIGURE 9: Effect of the bifacial PV panel separation from reflector on average electrical power output.

the bifacial solar cell equipped with a semimirror reflector and a diffuse reflector.

The panel adjustment variables ( $h$ and $\beta$ ) of the maximum points of each curve from of Figure 8 have been extracted and are plotted in Figure 10. The bifacial panel integrated with a diffuse reflector reaches the maximum power production at $10^{\circ}$ tilt and is relatively independent of panel separation. Meanwhile the optimum panel slope of the semimirror type reflector varies with separation of the panel.

The "maximum power point" in Figure 10 suggests the best parameters in order to achieve the maximum light to electrical energy conversion. Meanwhile, semimirror and diffuse type reflectors generate the same amount of energy at optimum adjustment.

Three distinguishable categories for semimirror reflector variation can be identified in Figure 10 and have been summarized as follow:

category (I): the majority of energy is provided by the front surface; small separation between panel and reflector does not permit significant capture of reflected light by the rear surface;

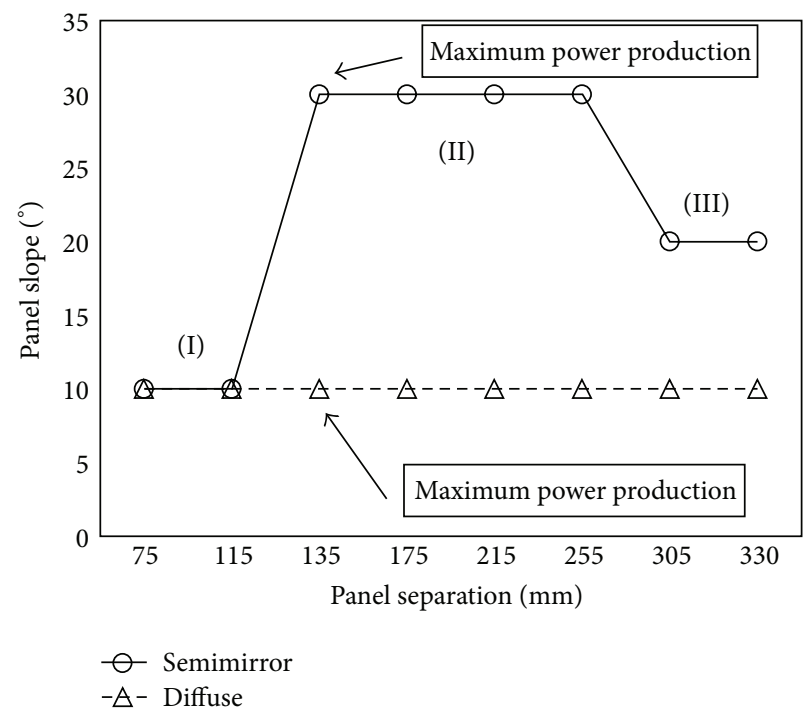

FIGURE 10: Optimum panel tilt and separation for maximum power generation as a function of panel-reflector separation.

category (II): large enough separation between the panel and the reflector leads to significant solar radiation capture by the rear surface;

category (III): For very large panel-reflector separations beyond $250 \mathrm{~mm}$, diffusedly reflected light can't be captured by the rear surface, hence the lower power output was observed. Therefore reducing the panel slope is necessary in order to maximize power production.

\section{Conclusions}

Two sets of experiment have been carried out to determine optical response of bifacial solar panels with an integrated external reflector. It has been determined that in contrast with 
conventional monofacial photovoltaic panels, the maximum power production does not occur at solar radiation normal to surface. There is a tradeoff between the electrical energy produced by direct solar radiation on front surface and reflected radiation on the rear surface, which depends on the properties of the reflector as well as the panel-reflector separation. In case of a bifacial panel parallel to the reflector, the maximum power is obtained at $115 \mathrm{~mm}$ separation from reflector and $10^{\circ}$ slope. PV cell separation higher than $250 \mathrm{~mm}$ from a diffused reflector led to higher solar radiation loss, where the electrical energy produced by the front surface plays the dominant role. Integrating an external reflector with the bifacial solar panel increases the total panel power production for a semimirror type and a diffuse type reflector by $20 \%$ and $15 \%$, respectively.

\section{References}

[1] A. Fahrenbruch and R. H. Bube, Fundamentals of Solar Cells, 1983.

[2] A. Luque, A. Cuevas, and J. M. Ruiz, "Double-sided $\mathrm{n}^{+}-\mathrm{p}-\mathrm{n}^{+}$ solar cell for bifacial concentration," Solar Cells, vol. 2, no. 2, pp. 151-166, 1980.

[3] A. Hubner, A. G. Aberle, and R. Hezel, "Temperature behavior of monofacial and bifacial silicon solar cells," in Proceedings of the 26th IEEE Photovoltaic Specialists Conference (PVSC '97), pp. 223-226, IEEE, Anaheim, Calif, USA, September-October 1997.

[4] R. Hezel, "Novel applications of bifacial solar cells," Progress in Photovoltaics, vol. 11, no. 8, pp. 549-556, 2003.

[5] M. Libra and V. Poulek, "A very simple solar tracker for space and terrestrial applications," Solar Energy Materials and Solar Cells, vol. 60, no. 2, pp. 99-103, 2000.

[6] T. Uematsu, K. Tsutsui, Y. Yazawa et al., "Development of bifacial PV cells for new applications of flat-plate modules," Solar Energy Materials and Solar Cells, vol. 75, no. 3-4, pp. 557566, 2003.

[7] T. Joge, Y. Eguchi, Y. Imazu, I. Araki, T. Uematsu, and K. Matsukuma, "Applications and field tests of bifacial solar modules," in Proceedings of the 29th IEEE Photovoltaic Specialists Conference, pp. 1549-1552, May 2002.

[8] K. J. Weber, V. Everett, P. N. K. Deenapanray, E. Franklin, and A. W. Blakers, "Modeling of static concentrator modules incorporating lambertian or v-groove rear reflectors," Solar Energy Materials and Solar Cells, vol. 90, no. 12, pp. 1741-1749, 2006.

[9] M. L. Vladislav Poulek and I. Persic, "Bifacial tracking concentrator TRAXLE 5X," in Proceedings of the 2nd International Workshop on Concentraing Photovoltaic Powerplant: Optical Design and Grid Conection, 2009.

[10] E. Ruíz-Vasquez, B. Robles-Ocampo, H. Canseco-Sánchez et al., "Photovoltaic/thermal solar hybrid system with bifacial PV module and transparent plane collector," Solar Energy Materials and Solar Cells, vol. 91, no. 20, pp. 1966-1971, 2007.

[11] M. Brogren and B. Karlsson, "Low-concentrating water-cooled PV-thermal hybrid systems for high latitudes," in Proceedings of the 29th IEEE Photovoltaic Specialists Conference, pp. 1733-1736, May 2002.

[12] U. Ortabasi, K. Firor, and M. Ilyin, "Low concentration photovoltaic module design using bifacial solar cells," in Proceedings of the 20th IEEE Photovoltaic Specialists Conference, pp. 13241326, September 1988.
[13] U. Ortabasi, "Performance of a $2 \mathrm{X}$ cusp concentrator PV module using bifacial solar cells," in Proceedings of the 26th IEEE Photovoltaic Specialist Conference (PVSC '97), Anaheim, Calif, USA, September-October 1997.

[14] T. Uematsu, Y. Yazawa, K. Tsutsui et al., "Design and characterization of flat-plate static-concentrator photovoltaic modules," Solar Energy Materials and Solar Cells, vol. 67, no. 1-4, pp. 441448, 2001.

[15] A. Moehlecke, I. Zanesco, A. C. Pan, T. C. Severo, and A. P. Mallmann, "Photovoltaic module with coloured diffuse reflectors," in Proceedings of the European Photovoltaic Solar Energy Conference, pp. 785-787, Munich, Germany, 2001.

[16] C. Duran, H. Deuser, R. Harney, and T. Buck, "Approaches to an improved IV and QE characterization of bifacial silicon solar cells and the prediction of their module performance," Energy Procedia, vol. 8, pp. 88-93, 2011. 

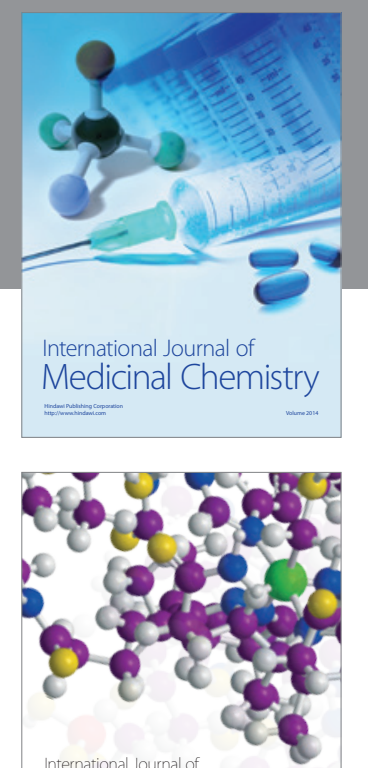

\section{Carbohydrate} Chemistry

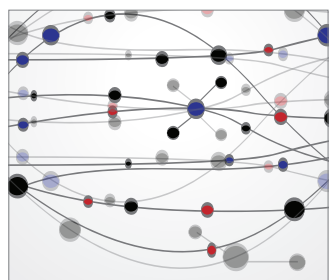

The Scientific World Journal
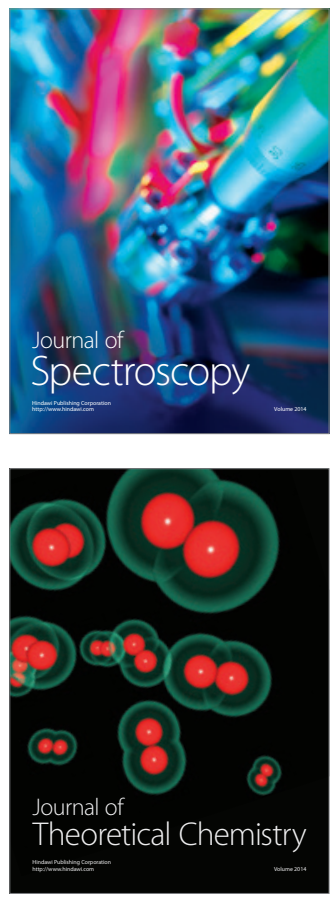
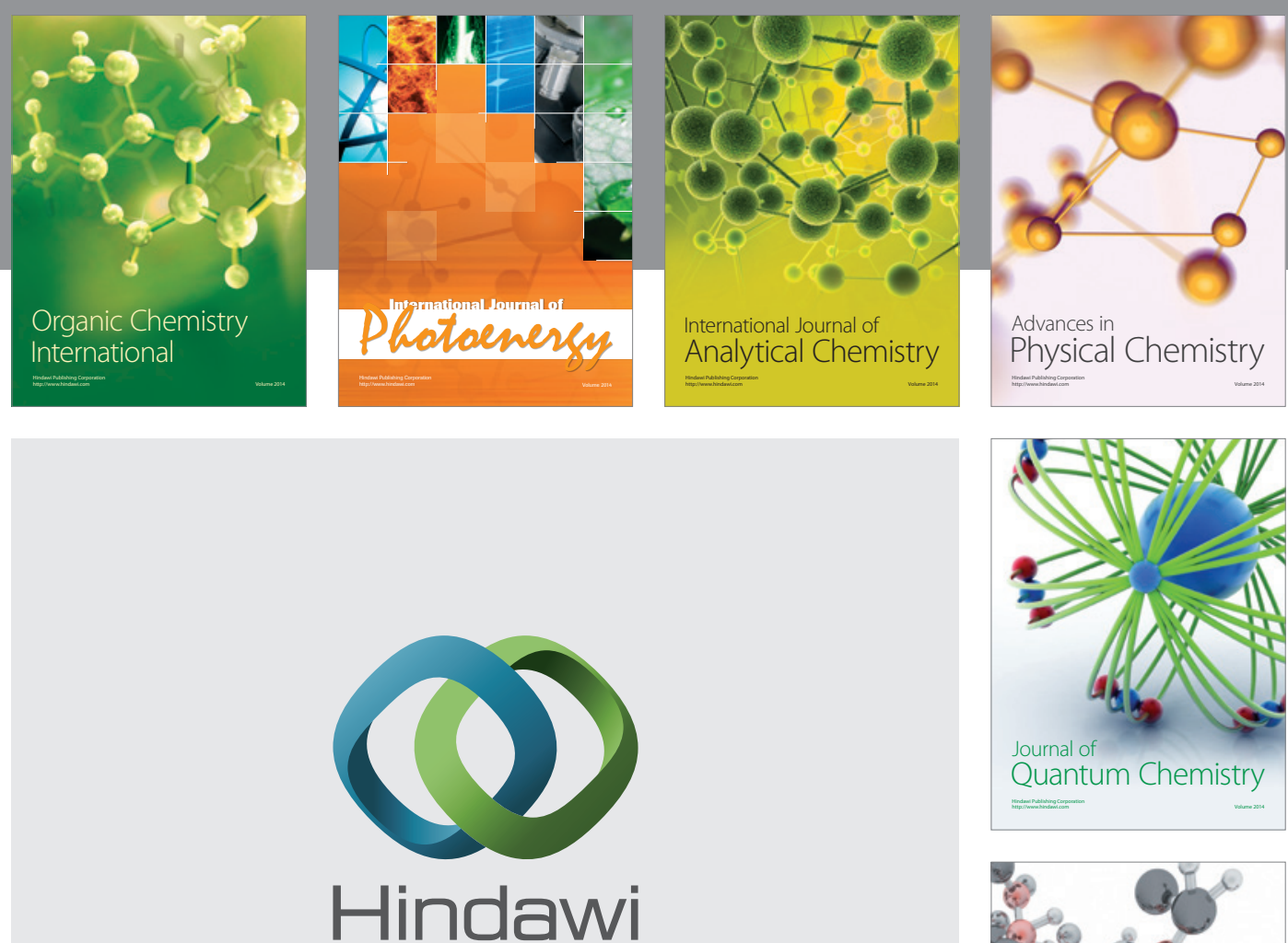

Submit your manuscripts at

http://www.hindawi.com

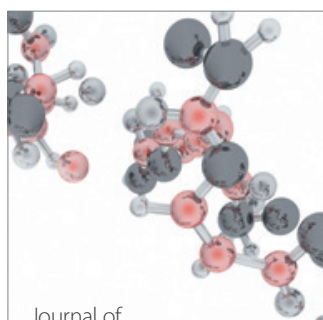

Analytical Methods

in Chemistry

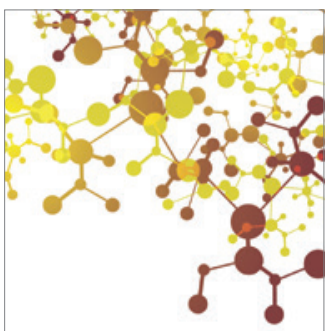

Journal of

Applied Chemistry

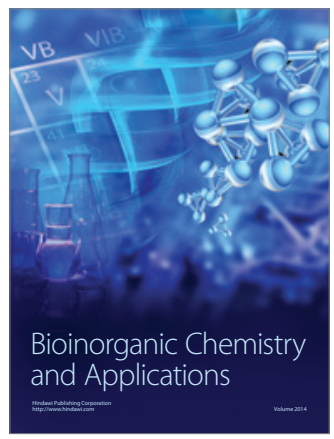

Inorganic Chemistry
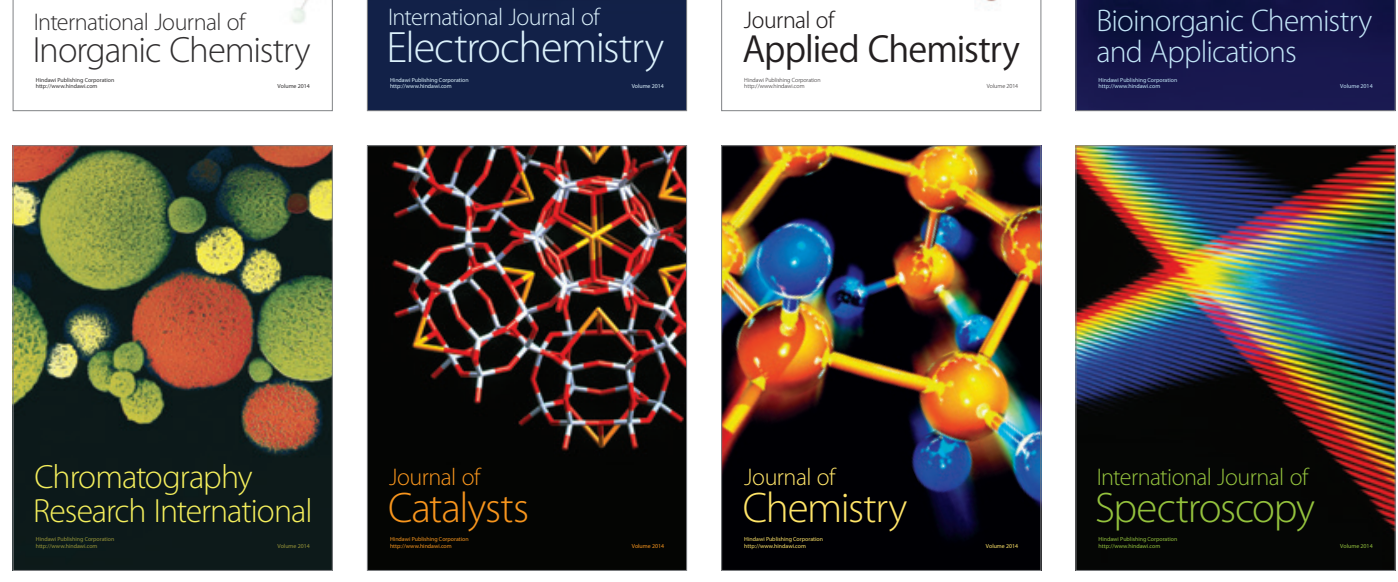